\title{
Experience of Nepali Indigenous Peoples on Free, Prior and Informed Consent (FPIC) (Perspective)
}

\author{
Pasang D. Sherpa * and Tunga B. Rai* \\ "Nepal Federation of Indigenous Nationalities, Climate Change REDD Program, Nepal \\ Corresponding author: pdsherpa2008@gmail.com
}

\section{INTRODUCTION}

Free, Prior and Informed Consent (FPIC) is a principle concerning the rights of indigenous peoples in the exercise of their collective rights over natural resources. It is recognized in the United Nations Declaration on the Rights of Indigenous Peoples (UNDRIP) and International Labour Organization's Convention on Indigenous and Tribal Peoples (ILO C 169). UNDRIP contains the mechanisms and processes regarding respect of indigenous peoples' rights to land, territories, resources, ancestral domain, their rights to selfdetermination and to cultural integrity (Article 10, Article 11 (Point 2), Article 19, Article 26 (Point 1), Article 26 (Point 2), Article 28 (Point 1), Article 29 (Point 2), and Article 32 (Point 2), ILO 169 Article 14 (Point 1), Article 15 (Point 1), and Article 16 (Point 2).

The four different elements, 'Free', 'Prior', 'Informed' and 'Consent', carry integral and substantial meaning to the whole principle of FPIC. Each of these terms has its own meaning, principles and processes of, and in, its implementation. AIPP (2012) states that the principle and the substance of each element of FPIC are interrelated and should not be taken or treated separately. The term 'Free' means independent process of decision-making. 'Prior' refers to the right to follow their own decisionmaking process for any projects that concern them before its implementation. 'Informed' refers to the right to have accurate, accessible, sufficient and culture-friendly information on matters for decision-making. 'Consent' is a collective and independent decision of affected indigenous communities after following their own process of decision-making. The first three elements (Free, Prior and Informed) qualify and set the conditions of 'consent' as a decisionmaking process. Therefore, 'consent' is required before any action takes place (Prior), independently decided (Free), and based on accurate and sufficient information (Informed) for it to be a valid outcome of a collective decision. Most importantly, the processes in each of these steps of FPIC should be fair and of good faith. Its implementation requires a framework of upholding the collective rights of indigenous peoples. Therefore, aspiration of FPIC is crucial for the indigenous peoples across the globe. It is relevant in order for them to ensure meaningful and effective participation in the decision-making process in the field that affects them directly and indirectly. Indeed, it ensures mutual respect and dignity of indigenous peoples, among others, rather than to confront with any actors of development.

\section{RATIONALE OF FPIC: WHY ARE INDIGENOUS PEOPLE ENTITLED TO FPIC?}

Indigenous peoples have a collective existence and, therefore, rely on each other for their survival and prosperity (AIPP 2012). They hold a common world-view of their 'indigenoushood' with distinct identity. Contrary to the fact that the industrial revolution focused on economic growth in Europe during the $18^{\text {th }}$ century, it had actually neglected the social and cultural assets of human being with a negative impact on indigenous peoples' livelihood in particular. Even 
after the end of World War II in 1940s, the concept, 'development', emerged and spread rapidly around the globe. It was heavily a unidimensional thought concentrated on assimilation of multiple life-ways, including of indigenous peoples' culture, into the so-called universal development ladder of living standards. These matters impacted indigenous peoples adversely.

In the context of Nepal, the first ever Law of the Land, Muluki Ain 1854, was discriminatory. The law legally placed indigenous peoples into the lower hierarchy of the caste system. Given the fact that indigenous peoples never belonged to the caste system and the hierarchy before, the justice system and the social, political and economic opportunities were subjected to the caste hierarchy that someone belongs to. Although the caste-based discrimination was legally abolished in 1963, multiple ways of exclusion and deprivation continued since it was deep-rooted in the mindset of society.

Along with time, development activities are taking its pace and have come a long way till date. New inventions are still impacting indigenous peoples in one way or the other. They are being pushed towards the verge of social exclusion. Multiple layers of inequality, political marginalization, economic deprivation, and cultural and symbiotic devaluation are the common experience of indigenous world because new plans, programmes, projects, policies and laws have had negative impact on indigenous peoples' multiple relationship with forest, land, territories and natural resources. There have been serious implications for indigenous peoples' health, traditional healing practices, territorial integrity, collective identity, ancestral domain, cultural integrity, livelihoods, customary practices and law, knowledge system, skills, social cohesion and well being, among others.

Due to these historical challenges among indigenous peoples, the decade-long discourse and efforts coined FPIC as a safeguard enshrined in the international measurement of collective rights of indigenous peoples in UNDRIP and ILO C 169. Hence, indigenous peoples are entitled to FPIC that applies to every matter, including policy formulations and/or adoption of legislative and administrative decisions that directly and/or indirectly affect them. Conducting FPIC allows indigenous peoples to exercise their collective rights and control over their ancestral domain and the respect to their cultural integrity and self-determination, especially on their own development as distinct peoples (Hill et al. 2010).

In order to respect diverse and peculiar ways of living and the collective rights of indigenous peoples, any external entity such as the government, corporations, institutions, organizations and project proponents need to seek an agreement, authorization and consent of indigenous communities as they are the rights holders on local natural resources upon which proposed project may have impacts. Therefore, FPIC is inevitable and is a collective undertaking of the members of community/ies that are involved in the collective decision-making processes (UN-REDD 2009). Nepal, as a party to the UNDRIP, ILO C 169 and other relevant international instruments, is itself obliged, and can get any company working in the area of indigenous peoples, to follow the FPIC process, while indigenous peoples have the rights to exercise FPIC.

\section{FPIC AS A SAFEGUARD IN REDD+}

The Conference of Parties (COP) 16 of the United Nations Framework Convention on Climate Change (UNFCCC) held in Cancun, Mexico in 2010 agreed upon the 7-point safeguard measures in order to adopt REDD+ as a means to mitigate climate change impact by preventing deforestation and forest degradation and conserving forests and biodiversity, with no negative impact on indigenous peoples and 
forest-dependent communities. As the parties to the convention agreed over the set of 'safeguards', governments are obliged to implement the agreed safeguards, including the rights of indigenous peoples mentioned in UNDRIP, ILO C 169 and in other international instruments of indigenous peoples' rights, including FPIC.

As the safeguards can be clustered into social and environmental sets, FPIC comes under the social safeguard. Parties to the convention agreed to implement FPIC in every mechanism and process related to REDD+ at all levels-local, sub-national, national and global. The safeguards entail effective and inclusive processes of FPIC of indigenous peoples at all levels. Parties agreed to develop a Safeguard Information System (SIS) in all REDD+ countries to provide information on how these social and environmental safeguards are being addressed and respected in the REDD+ activities. Later, in the COP 17 (2011) held in Durban, REDD+ countries agreed to make SIS report as a part of country's reporting mechanism to the UNFCCC secretariat. The Subsidiary Body for Scientific and Technical Advice (SBSTA) under UNFCCC is requested to develop guidelines on SIS to agree upon. An important implication of these agreements is the recognition of UNDRIP, including FPIC in REDD+ activities. This illustrates that the international negotiation on climate change and REDD+ has adopted FPIC.

In line with the UNFCCC agreement, the major delivery partners of the fund related to REDD+ initiatives have also adopted FPIC. For instance, Forest Carbon Partnership Facility (FCPF) of the World Bank and United Nations' REDD Programme (UN-REDD) have safeguard policies, including FPIC. Though the World Bank defines 'C' of FPIC as 'consultation' rather than 'consent', it has been addressing the issues of indigenous peoples. The Bank has been having dialogues and meetings with indigenous peoples at national, regional and global levels. It has a very clear policy about consultation, communication and participation of indigenous peoples in its programmes.

\section{FPIC IMPLEMENTATION IN REDD+ PROCESS IN NEPAL: GROUND REALITIES}

As mentioned in and guided by the REDD+ Readiness Preparation Proposal (R-PP), Government of Nepal (GoN) is trying to incorporate indigenous peoples' issues and rights in the Strategic Environmental and Social Assessment (SESA) and REDD+ Social and Environmental Standards (SES) standards. Similarly, since Nepal is carrying out some targeted programmes on climate change and REDD+ under UN-REDD, it is obliged to comply its work with the Social and Environmental Principles and Criteria (SEPC) of UN-REDD programme. So far, GoN has been working on drafting a framework for the National REDD+ Strategy. The Strategy may have impacts on indigenous peoples' traditional livelihoods, practices, knowledge system and identity (NEFIN 2012). Therefore, it is crucial to address the issues and challenges of all stakeholders, particularly the concerns of indigenous peoples. To minimize the negative impact and harness optimum benefits from REDD+, FPIC should be followed well in the REDD+ processes, including strategy formulation with effective and meaningful participation of all stakeholders in decisionmaking process at both local and national levels.

Nepal Federation of Indigenous Nationalities (NEFIN) has taken initiatives at both national and local levels for implementation of FPIC. Cases in the boxes below are some of the examples. 
Box 1: Initiative at National Level

NEFIN Climate Change and REDD+ Programme has been conducting awareness and capacity building of indigenous peoples and stakeholders concerned to educate them about FPIC on community-based REDD+ implementation. The programme developed an FPIC Manual for the Training of Trainers (ToT) and produced groups of resource persons across the country. They have been educating people at the community level. For the effective implementation of FPIC, NEFIN has also been working on Implementation Guidelines to facilitate proper implementation of FPIC. The process has already completed a series of consultations and meetings with Indigenous Peoples' Organizations (IPOs), their District Coordination Councils (DCCs), affiliated organizations and constituencies. The guideline contains necessary steps, mechanisms, processes and procedures of implementing FPIC, which can be used by all stakeholders, including government agencies, international non-government organizations (I/NGOs) and communitybased organizations (CBOs).

On the other hand, at the grassroots level, indigenous peoples are exercising FPIC not only in REDD+ activities but also in other related matters. For example, indigenous peoples of Ilam, in coordination with NEFIN DCC, are exercising the FPIC process in some development projects (see the cases in Box 2).
Box 2: Initiation at Local Level

Ilam municipality harvests drinking water from Gitlang River. The municipality demanded more drinking water for the increasing population in the town. The municipality officials eventually decided to supply more water from river. The sufferings and the story of the village near the source of water/river are, however, different. At the village level, indigenous peoples' livelihood depends on the river in many ways. Families belonging to indigenous communities run traditional water mills. On top of that, the river is sacred for them, for which they have been worshipping this river for generations. They have been managing and utilizing the water and have been attached to the river for time immemorial. Instead, the municipality simply planned to get water from the river. Indigenous peoples in the village realized that they were going to suffer from that water supply project, for which they then consulted NEFIN DCC. They held dialogues with the government personnel at the district level. They had a series of consultations and dialogues and agreed to the construction of pipelines on the condition that 50 per cent of the income from water use should go to the communities. The government would provide financial assistance for the schools in the village. They would provide health services in the district hospital to 50 households of the village free of cost. In order to keep the source of water clean, the government would assist in the construction of improved pig barns. Dialogue is ongoing to agree upon some more issues. The FPIC principle has been a tool to facilitate dialogue between the government and the communities concerned in Ilam. Source: Based on the interview with Kiran Sunuwar, NEFIN DCC Ilam, Chairperson 


\section{ISSUES, CHALLENGES AND RECOMMENDATIONS}

- FPIC implementation is a priority of both the FCPF World Bank and the UN-REDD guidelines. However, proper implementation of FPIC at local level is the major issue and the challenge of indigenous peoples in Nepal. Despite Nepal being a signatory of UNDRIP and the party for ILO C 169, GoN has not yet enacted a law for the proper implementation of FPIC. There are still gaps in policies and mechanisms to be set up for its implementation. The state seems reluctant in implementing FPIC. For this, Sterotypical mindset of bureaucracy has to be changed.

- Abolition of land tenure, collective rights and ownership of indigenous peoples on forest by the Forest Act 1993 contradicts with the FPIC principle. Community forestry violates the communal land tenure system and collective ownership of indigenous peoples over land. Representation of indigenous traditional institution by self/internal selection is another concern of indigenous peoples of Nepal.

- Awareness level among indigenous peoples, government officials and stakeholders varies. As a result, in some cases, FPIC is taken as a one-time event. In many cases, 'consent' is taken as one-way consultation. It is, however, a dynamic and ongoing process. Indigenous peoples may revise their decision depending upon the situation. They hold their right to say either 'yes' or 'no' and even to hold on their decision until they get enough information and time to make a collective decision.

- 'Consent' is a collective and independent decision of affected indigenous communities. It should provide them with time and space for their own decision-making process. Therefore, government and all stakeholders concerned need to understand the essence of FPIC and should engage in its implementation.

- Indigenous peoples often experience the lack of complete, accessible and culture-friendly information on matters affecting them. So, FPIC must be based upon a free and bottomup process while designing and implementing any project and programme, including REDD+ in Nepal.

Therefore, it is urgent to address these issues and challenges to respect indigenous peoples' rights for the continuation of their traditions, knowledge and culture with dignity that ultimately fosters justice, social inclusion and cohesion in the country.

\section{REFERENCES}

AIPP. 2012. Training Manual on the Free Prior and Informed Consent (FPIC) in REDD+. Asia Indigenous Peoples Pact (AIPP).

Hill, C., Lilywhite, S. and Simon, M. 2010. Guide to Free, perior and Informed Constent. Australia: Oxfam

NEFIN. 2012, Position Paper on Climate Change and REDD+. Kathmandu: Nepal Federation of Indigenous Nationalities.

UN-REDD. 2009. Operational Guidance: Engagement of Indigenous Peoples and other Forest Dependent Communities. United Nations REDD Programme. 